\title{
A Collaborative Effort to Establish a Convalescent Plasma Program in South Florida
}

\author{
By: Roberto L. Roman Laporte, DNP, RN, CMSRN, EBP-C; Edwina Brathwaite, PhD, MSN/Ed, MS/ \\ HSA, RN-BC
}

\begin{abstract}
On March 11, 2020, Miami-Dade County had its first diagnosed case of COVID-19 and quickly became the top hotspot of COVID-19 cases in Florida. Hospitals were challenged to find effective treatments to combat the virus. A collaborative effort between Doctors Hospital and Boca Raton Regional Hospital established a robust convalescent plasma program for critically ill patients diagnosed with COVID-19 within Baptist Health South Florida.

Keywords: Convalescent plasma, COVID-19, Coronavirus, SARS-CoV-2
\end{abstract}

\section{INTRODUCTION}

On March 11, 2020, Miami Dade County had its first diagnosed case of COVID-19. Soon after, the county would be known as one of the top hotspots for COVID-19 cases in the state of Florida (Florida Health, 2020). As of May 15, 2020, nearly 15,000 Miami-Dade County residents were diagnosed with COVID-19, with close to 2,500 residents requiring hospitalization and 535 COVID-19 related deaths reported by the Florida Department of Health (Florida Department of Health, 2020). As COVID-19 cases continued to spread throughout the county, hospitals were challenged to stabilize, treat, and support patients the best they could. Treatment methods for critically ill patients have included therapies such as: hydroxychloroquine, steroids, remdesivir, stem cell therapy, and convalescent plasma. Different studies, published globally, within the past few months, would try to show the risks and benefits of using such therapies until a targeted treatment or vaccine is established to fight COVID-19. The FDA would grant emergency authorization for such treatments, in the meantime.

Historically, convalescent plasma has been used to treat infections such as rabies, measles, polio and other pathogens and dates back to over a century when medications or vaccines were not readily available to treat or prevent certain outbreaks (American Society of Hematology, 2020;
Rubin, 2020). Recently, the FDA has provided recommendations for emergency use of convalescent plasma to treat critically ill patients diagnosed with COVID-19 (US Food and Drug Administration, 2020). The concept behind convalescent plasma is to take antibody rich plasma from a person who has recovered from COVID19 and administer it to a patient who is critically ill with the same infection. It is believed the antibody rich plasma would passively give patients the antibodies necessary to help combat the virus (American Society of Hematology, 2020). The purpose of this initiative was to establish a program to facilitate the donation and transfusion of convalescent plasma to critically ill patients diagnosed with COVID-19.

\section{COVID-19 INITIATIVE}

Doctors Hospital in Coral Gables in collaboration with Boca Raton Regional Hospital in Palm Beach County, established a convalescent plasma donor program within Baptist Health, in partnership with One Blood. Lincoln Mendez, CEO of Boca Raton Regional Hospital was the CEO leading the project in collaboration with Diane Amado-Tate, CNO of Doctors Hospital, and Becky Montesino-King, DNP, RN, NEA$\mathrm{BC}, \mathrm{CENP}$. The planning of the convalescent plasma program spanned across multiple departments. Doctors Hospital and Boca Raton Regional Hospital served as the donor/recipient 


\section{COVID-19 Special Edition}

processing centers to facilitate screening and matching of donors and recipients. One Blood facilitated the plasma collection and Baptist Health hospitals completed the process by transfusing the antibody rich plasma to critically ill patients diagnosed with COVID-19.

Nurse Navigators were appointed for the two regions of Baptist Health and were critical in facilitating the program. Nurse Navigator, Edwina Brathwaite, PhD, MSN/Ed, MS/HSA, RN-BC, Director of Nursing Practice Management, Diabetes, and Wound Care at Doctors Hospital, with supporting physician Dr. J. Perez Fernandez, Medical Director at Baptist Hospital of Miami, facilitated the process for the South Region and Nurse Navigator, Maureen Avella, RN Manager of the Cardiac Catherization Lab at Boca Raton Regional Hospital, with supporting physician Dr. S. Fahmy, CMIO at Boca Raton Regional Hospital, facilitated the North Region. The Nurse Navigators managed the physician, patient, and donor process to ensure FDA recommendations were followed.

\section{CONCLUSION}

Leadership support, interprofessional collaboration, regularly scheduled meetings, adaptability to changing circumstances and the collective effort of all involved led to a robust COVID-19 convalescent plasma program at Baptist Health. Through this initiative, all identified patients at the time of this manuscript who were eligible to receive convalescent plasma have been matched with donors. The overwhelming response of the local community to donate antibody rich plasma to critically ill patients with COVID-19 was inspiring. The program is now currently part of an expanded access program facilitated by the Mayo Clinic and is being evaluated for efficacy.

\section{DECLARATION OF INTEREST}

The authors report no conflicts of interest. The authors alone are responsible for the content and writing of the paper.

\section{AUTHORS}

Roberto L. Roman Laporte, DNP, RN, CMSRN, EBP-C, Nur se Scientist, Baptist Health South Florida, Miami, FL, US. Correspondence regarding this paper can be directed at: RobertRL@baptisthealth.net

Edwina Brathwaite, PhD, MSN/Ed, MS/HSA, RN-BC, Director, Nursing Practice Management, Diabetes \& Wound Care, BHSF Convalescent COVID-19 Plasma Program South Dade, Doctors Hospital, Coral Gables, FL, US. Correspondence regarding this paper can be directed at:

EdwinaB@baptisthealth.net

\section{REFERENCES}

American Society of Hematology. (2020). COVID-19 and convalescent plasma: Frequently asked questions. https://doi.org/10.1101/2022.04.06.22273542

Florida Department of Health. (2020). Florida's COVID-19 data and surveillance dashboard. https://floridahealthcovid19.gov/

Florida Health. (2020). Florida Department of Health announces new positive COVID-19 cases in Florida. https:// doi.org/10.25270/con.2021.10.00006

Rubin, R. (2020). Testing an old therapy against a new disease: Convalescent plasma for COVID-19. JAMA Network. https:// doi.org/10.1001/jama.2020.7456

One Blood. (2020). Miami Mayor Francis Suarez becomes first COVID 19 convalescent plasma donor in Florida. https:// www.oneblood.org/media/press-releases/ miami-mayor-francis-suarez-becomes-firstcovid-19-convalescent-plasma-donor-inflorida.stml 


\section{COVID-19 Special Edition}

US Food and Drug Administration. (2020).

Recommendations for investigational

COVID-19 convalescent plasma. https://

www.fda.gov/vaccines-blood-biologics/

investigational-new-drug-ind-or-device-

exemption-ide-process-cber/

recommendations-investigational-

covid-19-convalescent-plasma https://

doi.org/10.1055/b-0035-108566 